\title{
Bone biomarker for the clinical assessment of osteoporosis: recent developments and future perspectives
}

\author{
Tsung-Rong Kuo ${ }^{1,2}$ and Chih-Hwa Chen ${ }^{3, *^{*}}$
}

\begin{abstract}
Bone biomarkers included formation, resorption and regulator are released during the bone remodeling processes. These bone biomarkers have attracted much attention in the clinical assessment of osteoporosis treatment in the past decade. Combination with the measurement of bone mineral density, the clinical applications of bone biomarkers have provided comprehensive information for diagnosis of osteoporosis. However, the analytical approaches of the bone biomarkers are still the challenge for further clinical trials. In this mini-review, we have introduced the functions of bone biomarkers and then recently developed techniques for bone biomarker measurements have been systematically integrated to discuss the possibility for osteoporosis assessment in the early stage.
\end{abstract}

Keywords: Bone biomarker, Bone formation, Bone resorption, Regulators, Bone turnover, Osteoporosis

\section{Background}

Osteoporosis is a worldwide disease with reduction of bone mass and decrease of bone strength to result in bone fragility and fracture. Based on the report of World Health Organization (WHO), the disease of osteoporosis has been diagnosed by bone mineral density (BMD) at the hip and/or the spine at least 2.5 standard deviations below in comparison with the bone mass of young healthy adults as determined by dual-energy X-ray absorptiometry (DXA) [1]. The people with osteoporosis are steadily increased because of aging society occurring worldwide. There are about 200 million people are suffered from osteoporosis in the word and approximately 8.9 million fractures are caused by osteoporotic fracture [2]. In the osteoporotic fractures, hip fractures have led to mortality rates up to $20-24 \%$ within the first year and then the death rate has steadily increased for at least 5 years [3]. After hip fractures, the survivors may lose the capability of action and independence with $40 \%$ unable to walk independently and $60 \%$ requiring assistance at least 1 year. Due to the loss of capability, around

\footnotetext{
* Correspondence: chihhwache@tmu.edu.tw

${ }^{3}$ Bone and Joint Research Center, Department of Orthopedics and

Traumatology, Taipei Medical University Hospital, Taipei 11031, Taiwan

${ }^{4}$ School of Medicine, College of Medicine, Taipei Medical University, Taipei

11031, Taiwan

Full list of author information is available at the end of the article
}

$33 \%$ patients are totally dependent or in a nursing home in the year following a hip fracture. Nowadays, osteoporosis is a major concern of public health because of its healthcare cost. Moreover, the fracture caused by osteoporosis is the most important factor for the decreases of quality of life and survival rate in aging people.

Osteoporosis is a silent disease without obvious symptom and evidence until occurrence of fracture. Early diagnosis of osteoporosis is the key issue for efficient treatment and for identification of osteoporotic patient with high risk of fracture. At present, diagnosis of osteoporosis and assessment of fracture risk are based on the quantitative analysis of BMD by DXA. However, the gold standard method of BMD assessment of bone mass by DXA only partially provides the information about bone strength. The osteoporosis is characterized by bone fragility. Bone fragility is evaluated by its microarchitectural quality which is identified by all bone features such as microarchitecture, microdamage and remodeling rates with the influence of bone's ability for resistant fracture. The two-dimensional technique of DXA reveals the intrinsic limitations to discriminate cortical from cancellous bone and characterize changes because of bone geometry. Recently, several approaches have been developed to provide supplementary information for the assessment of fracture risks except BMD. For example, 
quantitative computed tomography (QCT) has been developed to evaluate bone loss $[4,5]$. In QCT, the true value of mineral density for trabecular bone has been obtained from cortical portion of bone [6]. Moreover, the instrument of ultrasound has been applied to examine bone condition and fracture risk $[7,8]$. The novel ultrasonic instrument is the first tool to characterize bone and assess microarchitecture with the detection of central axial reference sites (lumbar vertebrae and proximal femur) without the uses of ionizing radiations. However, these imaging techniques still have some limitations such as bulky device, high cost and limited accessibility to impede their applications for widespread uses and primary care inspection. Besides imaging techniques, the alternative method is still essential to be developed for the early and correct diagnosis of osteoporosis because the accurate diagnosis of osteoporosis in the early stage leads to a better management for the prevention and treatment.

The biomarkers of bone turnover have been investigated in the past decade. As shown in Fig. 1, the mechanism of bone remodeling is composed by bone resorption and bone formation [9]. Bone biomarkers are produced from the bone remodeling process included bone formation biomarkers, bone resorption biomarkers and regulators of bone turnover. Detections of bone metabolism have been studied with the biomarkers of enzymes, proteins and by-products during the bone remodeling process [10-13].
Various biomarkers are now available for specific and sensitive assessment of the rate for bone formation and bone resorption as shown in Table 1 [14]. For example, the bone formation biomarkers are total alkaline phosphatase (ALP), bone-specific alkaline phosphatase (BALP), osteocalcin (OC), procollagen type $1 \mathrm{~N}$-terminal propeptide (P1NP) and procollagen type $1 \mathrm{C}$-terminal propeptide (P1CP). The bone resorption biomarkers are hydroxyproline (HYP), hydroxylysine (HYL), deoxypyridinoline (DPD), pyridinoline (PYD), bone sialoprotein (BSP), osteopontin (OP), tartrate-resistant acid phosphatase 5b (TRAP 5b), carboxy-terminal crosslinked telopeptide of type 1 collagen (CTX-1), amino-terminal crosslinked telopeptide of type 1 collagen (NTX-1) and cathepsin K (CTSK). The regulators of bone turnover are receptor activator of NF-kB ligand (RANKL), osteoprotegerin (OPG), dickkopf-1 (DDK-1) and sclerostin. These biomarkers are useful to provide the early assessment of osteoporosis when the BMD measurement of DXA does not offer enough information to make the diagnosis. Therefore, the combination of BMD measurement by DXA and bone biomarker detections shows the great potential to improve the early assessment of people with the high risk of osteoporosis. Herein, we present the recent studies and breakthroughs in the detections of bone related biomarkers for the assessment of osteoporosis. We hope to provide a comprehensive mini-review starting from

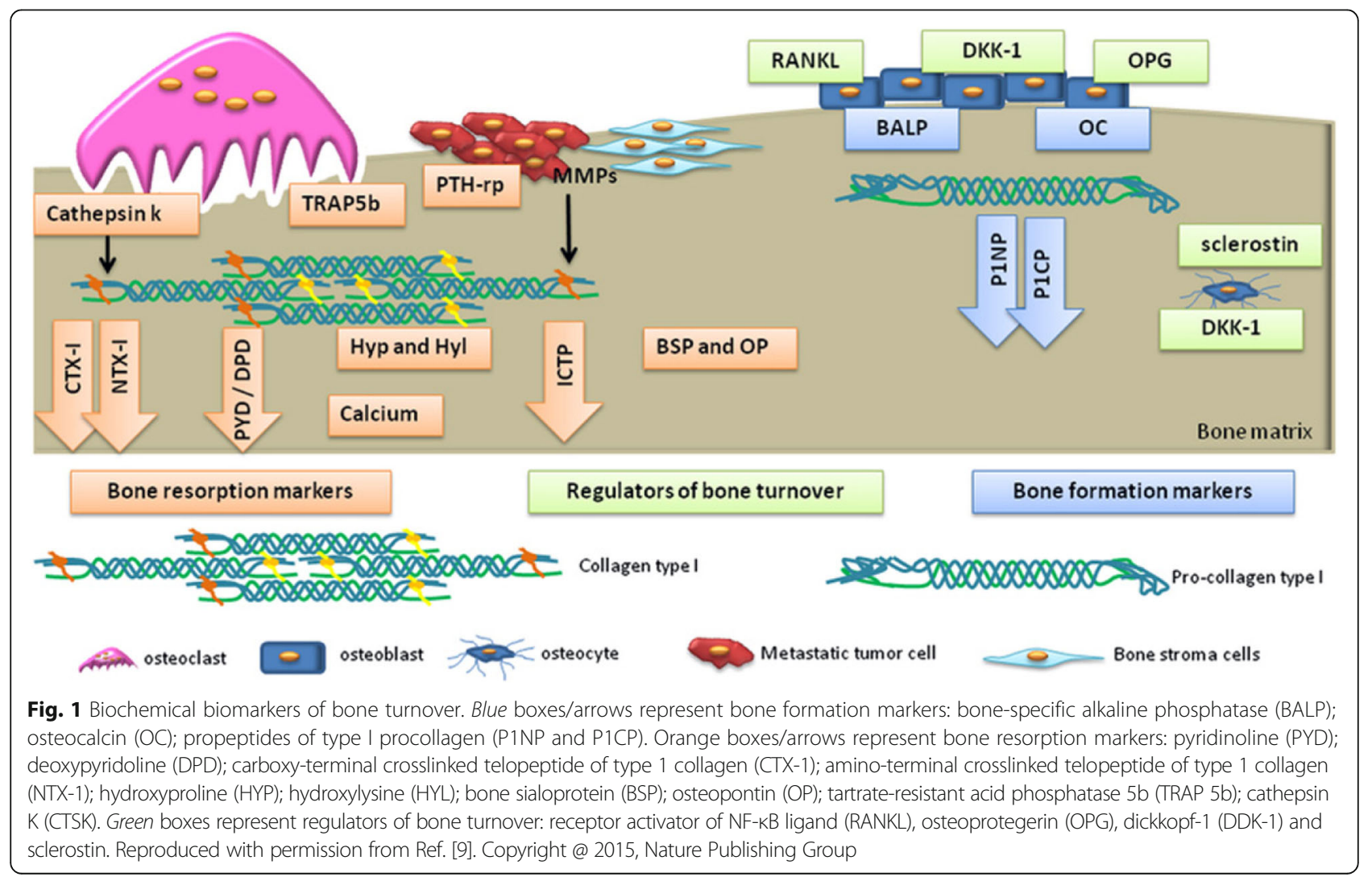


Table 1 Summary of detection techniques for bone biomarkers

\begin{tabular}{|c|c|c|c|}
\hline Biomarker & Method & Concentration & Reference \\
\hline Total ALP & standard Technicon Auto-analyzer & $113 \mathrm{U} / \mathrm{L}$ & {$[12]$} \\
\hline Total ALP & Roche COBAS Integra 800 & $>129 \mathrm{U} / \mathrm{L}$ & [13] \\
\hline Total ALP & Olympus AU 5200 analyzer & $64.8-79.7 \mathrm{U} / \mathrm{L}$ & {$[14]$} \\
\hline BALP & enzyme immunoassay & 24.9-19.7 U/L & {$[24]$} \\
\hline BALP & enzyme immunoassay & $66.4 \pm 8.7 \mathrm{U} / \mathrm{L}$ & {$[25]$} \\
\hline OC & antibody immunoassay & $4.1 \pm 0.5 \mathrm{ng} / \mathrm{mL}$ & {$[27]$} \\
\hline OC & ELISA & $16.16 \pm 4.5 \mathrm{ng} / \mathrm{mL}$ & {$[28]$} \\
\hline P1NP & Elecsys 2010 automated analyzer & $54.1 \mu \mathrm{g} / \mathrm{L}$ & [29] \\
\hline P1CP & radioimmunoassay & $97-116 \mathrm{ng} / \mathrm{mL}$ & {$[32]$} \\
\hline HYP & Bergman and Loxley method & $34.7 \mathrm{mg} / \mathrm{g}$ creatinine & {$[35]$} \\
\hline GHYL & HPLC & $1.35 \pm 0.82 \mathrm{mmol} / \mathrm{mol}$ & {$[39]$} \\
\hline GHYL & HPLC & $1.93-6.07 \mu \mathrm{mol} / \mathrm{L}$ & {$[40]$} \\
\hline DPD & HPLC & $11.3-22.3 \mathrm{nmol} / \mathrm{L}$ & {$[40]$} \\
\hline DPD & chemiluminescence immunoassay & $4.7 \mathrm{nmol} / \mathrm{L}$ & {$[42]$} \\
\hline DPD & enzyme immunoassay & $4.4 \mathrm{nmol} / \mathrm{L}$ & {$[42]$} \\
\hline PYD & HPLC & $28.8 \mu \mathrm{mol} / \mathrm{mol}$ creatinine & {$[45]$} \\
\hline BSP & radioimmunoassay & $12.1 \pm 5.0 \mu \mathrm{g} / \mathrm{L}$ & {$[48]$} \\
\hline BSP & radioimmunoassay & $8.0 \mu \mathrm{g} / \mathrm{L}$ & {$[49]$} \\
\hline $\mathrm{OP}$ & ELISA & $20.75 \pm 5.36 \mathrm{ng} / \mathrm{mL}$ & {$[51]$} \\
\hline TRAP 5b & enzyme immunoassay & $4.0 \mathrm{U} / \mathrm{L}$ & [54] \\
\hline TRAP 5b & enzyme immunoassay & $3.40 \pm 0.87 \mathrm{U} / \mathrm{L}$ & {$[55]$} \\
\hline CTX-1 & ELISA & $0.17-0.30 \mathrm{ng} / \mathrm{ml}$ & {$[56]$} \\
\hline NTX-1 & ELISA & $37 \pm 15 \mathrm{nmol} \mathrm{BCE} / \mathrm{mmol} \mathrm{Cr}$ & {$[57]$} \\
\hline CTSK & ELISA & $10.17 \mathrm{pmol} / \mathrm{L}$ & [59] \\
\hline RANKL & ELISA & $0.08 \mathrm{pmol} / \mathrm{L}$ & [61] \\
\hline OPG & ELISA & $1.8 \mathrm{pmol} / \mathrm{L}$ & {$[61]$} \\
\hline DDK-1 & ELISA & $34.3 \mathrm{pmol} / \mathrm{L}$ & [65] \\
\hline Sclerostin & ELISA & $29.5 \mathrm{pmol} / \mathrm{L}$ & {$[65]$} \\
\hline
\end{tabular}

the functions of bone biomarkers included bone formation, bone resorption and regulator of bone turnover to the applications in osteoporotic assessment at the end.

\section{Bone formation biomarkers}

Total alkaline Phosphatase (ALP)

Alkaline phosphatase is an enzyme found in the bloodstream. The different forms of ALPs can break down proteins in the human body. Most of ALPs are produced in liver and some of ALPs are generated in the bones, intestines and kidneys. The total ALP is examined by the measurement of the amount of alkaline phosphatase enzyme in the bloodstream. The measurement of total ALP only needs a simple blood draw and is often a routine part of blood tests. The normal levels of ALP with people are various by age, blood type, gender and pregnancy. Unusual concentrations of ALP in blood generally indicate an issue with liver, gall bladder, or bones. The ALP test can be used for diagnosis of bone problems such as rickets, osteomalacia and Paget's disease. The ALP level also can be applied to check the treatment efficiency for the above conditions. For example, the standard Technicon Autoanalyzer has been used to measure the serum ALP for osteoporotic patients with inflammatory bowel disease [15]. The spinal bone mineral content has revealed significant correlations with serum total ALP. Recent study has also shown that the activity of serum total ALP $>129 \mathrm{U} / \mathrm{L}$ is used as an indicator for osteoporosis in men [16]. Moreover, the decrease of total ALP has been demonstrated with the treatment with alendronate from $79.7 \mathrm{U} / \mathrm{L}$ to $64.8 \mathrm{U} / \mathrm{L}$ [17]. The results indicate that total ALP can be used as 
an indicator to reflect the efficiency of drug treatment for osteoporosis. However, small change and wide extensive range of total ALP may be led to wrong diagnosis of osteoporosis for postmenopausal women.

\section{Bone-specific alkaline Phosphatase (BALP)}

With normal liver function in adults, about $50 \%$ of total ALP is produced from bone in serum. The ALP isoenzymes produced from bone are difficult to distinguish with the isoenzymes from liver because they are only different by posttranslational glycosylation. Several approaches have been applied to specific measurements of BALP such as agarose electrophoresis, heat and chemical inactivation, wheat germ agglutinin precipitation, wheat germ agglutinin-high performance liquid chromatography, immunoradiometric assay and enzyme immunoassay [18-26].

For the enzyme immunoassay of BALP, the detection limit is $0.7 \mathrm{U} / \mathrm{L}$ and the mean values are $24.9 \pm 7.0 \mathrm{U} / \mathrm{L}$ and $19.7 \pm 5.6 \mathrm{U} / \mathrm{L}$ for men and premenopausal women, respectively. [27] With osteoporosis, the BALP activity of $66.4 \pm 8.7 \mathrm{U} / \mathrm{L}$ has been detected with women aged over 59 years [28]. As an indicator of osteoblastic activity, the measurement of BALP is applied as the assistance for the management of osteoporosis in premenopausal and postmenopausal women.

\section{Osteocalcin (OC)}

Osteocalcin, also known as bone gamma-carboxyglutamic acid-containing protein, is a small protein composed by 49 amino acids. OC is synthesized by mature osteoblasts, odontoblasts and hypertrophic chondrocytes. Moreover, $\mathrm{OC}$ is the most abundant non-collagenous protein in bone comprised about $2 \%$ of total protein in the human body. OC produced by osteoblasts plays an important role for metabolic regulation, bone mineralization and calcium ion homeostasis [29]. OC has been demonstrated that the level of serum OC is highly correlated with the increase of BMD during treatment with bone formation drugs for osteoporosis. Serum OC has been considered a specific biomarker of osteoblast function for evaluation of bone formation rate in osteoporosis. In many studies, osteocalcin has been demonstrated as an important biomarker to investigate the efficiency for the drug on bone formation. For instance, with the RNAse-enriched-LF supplementation, the change of OC from baseline $(7.2 \pm 2.8 \%)$ has shown a promising and favorable effect in postmenopausal women [30]. Furthermore, the mean levels of osteocalcin have revealed a significant difference between the postmenopausal osteoporotic $(16.16 \pm 4.5 \mathrm{ng} / \mathrm{ml})$ and nonosteoporotic $(11.26 \pm 3.07 \mathrm{ng} / \mathrm{ml})$ women [31]. The uses of osteocalcin as a bone formation biomarker could provide the advantages such as tissue specificity, wide availability and low variation. The bone remodeling biomarker of serum OC may be useful for the assessment of osteoporosis and for the prediction of the fracture risk in elderly persons, especially in women.

\section{Procollagen type $1 \mathrm{~N}$-terminal Propeptide (P1NP)}

Type 1 collagen can be found in the organic bone matrix (> 90\%), which is developed in bone from procollagen type 1 . Procollagen type 1 is synthesized by fibroblasts and osteoblasts. Procollagen type 1 has $\mathrm{N}$-terminal and C-terminal extensions, which are removed by specific proteases during conversion of procollagen to collagen. The procollagen type 1 included $\mathrm{P} 1 \mathrm{CP}$ and $\mathrm{P} 1 \mathrm{NP}$ are subsequently conjugated onto the bone matrix. The bone formation biomarker of P1NP is a specific indicator of type 1 collagen deposition. P1NP is released during the formation of type 1 collagen into the intracellular space and P1NP eventually exists in the blood stream. P1NP is usually released in the trimeric structure (derived from the trimeric collagen structure) and then is rapidly broken down to a monomeric form by thermal degradation effects. Antibodies of P1NP are used to detect the trimeric structure of P1NP by enzyme-linked immunosorbent assay (ELISA) or radioimmunoassay. Recently, for the postmenopausal women with osteoporosis participating in the Parathyroid Hormone and Alendronate for Osteoporosis study, the mean value $(54.1 \mu \mathrm{g} / \mathrm{L})$ of total P1NP before initiating therapy is $74 \%$ higher than that in healthy premenopausal women with the age above 35 [32]. P1NP has been demonstrated to be a more sensitive bone biomarker to measure the bone formation rate in osteoporosis. The measurement of P1NP is being developed for clinical application.

\section{Procollagen type $1 \mathrm{C}$-terminal Propeptide (P1CP).}

$\mathrm{P} 1 \mathrm{CP}$ is a single protein with molecular weight of $115 \mathrm{kDa}$ containing mannose-rich carbohydrate side chains inserted post-translationally. PICP is cleared by liver endothelial cells via the mannose receptor and therefore has a short serum half-life of 6-8 $\mathrm{min}[33,34]$. Recent study shows that the P1CP in serum is used as a biomarker of bone formation to evaluate the effect of nandrolone decanoate and female sex hormones. The mean initial PICP concentration in the women with a vertebral fracture $(97 \pm 23 \mathrm{ng} / \mathrm{mL})$ is significantly lower than that in the women with a forearm fracture $(116 \pm 27 \mathrm{ng} / \mathrm{mL})$ [35]. Currently, both of P1NP and $\mathrm{P} 1 \mathrm{CP}$ are analyzed by specific immunoassays. However, for the analyses of procollagen type 1, the biomarker of P1NP is more extensively investigated in the literature than that of P1CP. Several studies have also demonstrated good correlations between serum P1CP levels and the rate of bone formation [36]. 


\section{Bone Resorption biomarkers Hydroxyproline (HYP)}

HYP is an amino acid derived from the post-translational hydroxylation of proline. HYP provides about $12-14 \%$ of the total amino acid content of mature collagen. During the degradation of bone collagen, about $90 \%$ of the HYP is released and then the HYP is primarily metabolized in the liver [37]. The level of HYP has significantly increased in urine with postmenopausal osteoporosis women in comparison with the postmenopausal nonosteoporosis women [38]. The increase of urinary HYP indicates that the degradation of collagen type I from the bone matrix is raised in osteoporotic women. Although the HYP is principally used as a resorption biomarker, about $10 \%$ of the HYP is derived from newly synthesized procollagen peptides during bone formation. Moreover, HYP can be found in other tissues such as skin and cartilage and also can be liberated from the metabolism of elastin and C1Q [39]. HYP is consequently considered as a nonspecific bone resorption biomarker of collagen turnover. The use of HYP has been replaced by more sensitive and specific biomarkers for the assessment of osteoporosis [40].

\section{Hydroxylysine (HYL)}

HYL is an amino acid derived from a post-translational hydroxy modification of lysine. HYL has two forms included galactosyl hydroxylysine (GHYL) and glucosylgalactosyl-hydroxylysine (GGHYL) [41]. GHYL and GGHYL are both released into the circulation during collagen degradation. GHYL is a more specific for bone biomarker because it is only derived from bone resorption. On the other hand, GGHYL can be found in skin and complement molecule of C1Q. Therefore, GHYL is considered as a better bone resorption biomarker than GGHYL and HYP. In previous work, the concentration of GHYL in urinary excretion has been applied to evaluate the occurrence of fracture in postmenopausal osteoporotic women without fragility fractures and postmenopausal osteoporotic women with fragility fractures [42]. The high levels of GHYL in fracture patients suggest a possible defect in bone collagen and the urinary GHYL may indeed identify such an abnormality. Furthermore, GHYL can be easily measured without preanalytical hydrolysis and extraction by high performance liquid chromatography (HPLC) [43]. Although the GHYL has revealed the potential as a biomarker of bone resorption, the use of GHYL has not been extensively studied for the assessment of osteoporosis and the evaluation of osteoporotic treatment. The clinical application of GHYL is still limited because of the absence of facile routine methods for its measurement.

\section{Deoxypyridinoline (DPD)}

DPD is a molecule to mechanically stabilize collagen by crosslinking between individual collagen peptides [44] During the process of bone resorption, the crosslinked collagens are proteolytically broken down and then the DPD is released into the circulation and excreted by urine. Most of DPD are found in the bone and dentin. Therefore, DPD is used as a specific biomarker for bone resorption. In previous work, the DPD has been pretreated with preanalytical hydrolysis and extraction before HPLC analysis because DPD is excreted in the urine in free (40\%) and peptide-bound (60\%) forms. To improve the accuracy, the peptide-bound form is transferred into free form for the HPLC measurement. The drawbacks for HPLC measurement of DPD are complicated procedure and variable recovery [43]. Recently, the automated chemiluminescence immunoassay and enzyme immunoassay have been developed for the direct detection of urinary free DPD. The experimental results of chemiluminescence immunoassay and enzyme immunoassay methods have shown the correlation with HPLC measurement of urinary free DPD [45-47]. The measurements of free DPD in urine by the immunoassay approaches have provided the possibility for the clinical application in the monitoring of patients with bone pathology and metabolic bone disease.

\section{Pyridinoline (PYD)}

Collagen crosslink of PYD is produced during the extracellular maturation of fibrillar collagens and released into the circulation from degradation of mature collagens. Previous study shows that the PYD exhibits longterm chemical stability in both the free and conjugated forms by HPLC analyses [48]. However, PYD is found in cartilage, bone, ligaments and blood vessels. Therefore, PYD is a non-specific bone resorption biomarker in comparison with DPD.

\section{Bone Sialoprotein (BSP)}

BSP is a phosphorylated glycoprotein with an apparent molecular weight of $60-80 \mathrm{kDa}$ [49]. BSP is an element of mineralized tissues such as bone, dentin, cementum and calcified cartilage. BSP is an important component of the bone extracellular matrix and has been demonstrated to for the formation of approximately $8 \%$ of all non-collagenous proteins found in bone and cementum [50]. BSP is generated by osteoblasts, odontoblasts and osteoclasts. Therefore, BSP is considered as an important factor for cell-matrix adhesion processes and stimulation of osteoclast-mediated bone resorption. Many studies have developed immunoassays for the measurement of BSP in serum. For example, radioimmunoassay measurements have obtained mean serum BSP concentrations of $12.1 \pm 5.0 \mu \mathrm{g} / \mathrm{L}$ from 90 healthy controls and $32.3 \pm 17.3 \mu \mathrm{g} / \mathrm{L}$ from patients 
with Paget disease [51]. Serum levels of BSP have been also demonstrated the significant correlation with BALP and OC in osteoporosis patients [52]. BSP has shown great potential as a bone resorption biomarker for osteoporotic assessment.

\section{Osteopontin (OP)}

OP is a phosphorylated glycoprotein expressed by transformed cells, macrophages, activated T-lymphocytes, specialized epithelial cells and bone cells [53]. Recent study shows that women with OP over-expression reveal less resistance to postmenopausal osteoporosis than women with normal OP levels [54]. The levels of plasma OP could be used as a biomarker to evaluate the treatment of intermittent parathyroid hormone in menopausal osteoporosis.

\section{Tartrate-resistant acid Phosphatase 5b (TRAP 5b)}

TRAP $5 \mathrm{~b}$ is normally secreted by osteoclasts during bone resorption $[55,56]$. Thus, TRAP $5 \mathrm{~b}$ is used as a reference for osteoclast activity and numbers. In the circulation, the hydrolyzed TRAP $5 \mathrm{~b}$ is metabolized in the liver and then excreted in the urine. TRAP $5 \mathrm{~b}$ can be specifically detected in serum by immunoassays. Previous report shows that serum TRAP $5 \mathrm{~b}$ has been used to identify limited or extensive bone metastasis in breast cancer patients [57]. Furthermore, serum TRAP 5b has been applied to monitor the efficiency of alendronate treatment [58]. The bone resorption biomarker of TRAP $5 \mathrm{~b}$ is extensively studied and revealed good specificity and high sensitivity in comparison with other bone biomarkers.

\section{Carboxy-terminal Crosslinked Telopeptide of type 1 collagen (CTX-1),}

Telopeptides of type 1 collagen are extensively investigated and used bone resorption biomarkers included carboxy-terminal crosslinked (CTX-1) and aminoterminal crosslinked (NTX-1). CTX-1 and NTX-1 are both are released during collagen degradation. ELISA is used to measured CTX-1 with a monoclonal antibody against an octapeptide sequence (EKAHD- $\beta$-GGR) in the $\alpha-1$ (I) chain of the $\beta$-isoform. Recent study has shown that CTX-1 is a specific and sensitive biomarker of bone resorption that can rapidly indicate the response to bisphosphonate therapy for postmenopausal osteoporosis [59]. However, serum CTX-1 is influenced by food intake and blood withdrawal must take place in the fasting state because food intake substantially decreases the levels of CTX-1 [60].

\section{Amino-terminal Crosslinked Telopeptide of type 1 collagen (NTX-1)}

NTX-1 is stable in urine at room temperature for up to $24 \mathrm{~h}$ and is usually quantified by ELISA with urine sample. The urinary NTX-1 has been used as a bone resorption biomarker to assess the risk of fracture in postmenopausal women [60]. The urinary NTX-1 is selected as the preferred biomarker compared with serum CTX-1 for practical application because it is not affected by food intake and it prevents blood withdrawal.

\section{Cathepsin K (CTSK)}

Cathepsins are members of the cysteine protease family with 11 isoforms. CTSK is defined by its high specificity for kinins. CTSK is mainly expressed at the ruffled border of actively resorbing osteoclasts [61]. Osteoclasts secrete CTSK into bone resorption defect for degradation of bone matrix proteins included type 1 collagen, osteopontin and osteonectin. Therefore, CTSK is an important factor in process of bone resorption. The level of CTSK has revealed significantly different between controls and patients with osteoporosis [62]. The result indicates that serum level of CTSK could serve as a potential biomarker for fracture prediction and bonemineral density.

\section{Regulators of bone turnover Receptor activator of NF-KB ligand (RANKL)}

During the process of bone remodeling, osteoblasts produce RANKL and OPG to regulate the differentiation and maturation of osteoclasts. Recently, dextromethorphan has been demonstrated the inhibition of RANKL-induced osteoclastogenesis and bone resorption by abrogating the activation of NF- $\mathrm{kB}$ signaling in vitro. The oral administration of dextromethorphan improves ovariectomyinduced osteoporosis in vivo [63]. Serum levels of RANKL from humans have been observed for assessments of the states in metabolic bone diseases [64]. Although the serum RANKL has been studied for fracture risk prediction and evaluation of the response from osteoporosis treatment, many works still need to be investigated for the clinical application of RANKL.

\section{Osteoprotegerin (OPG)}

OPG is generally considered to be a secreted soluble receptor and is produced by many different tissues and cell types including osteoblasts. The role of OPG is used as a decoy receptor for RANKL and inhibitor of osteoclastogenesis [65]. Studies in mice have revealed that the OPG knockout mouse develops severe osteoporosis, whereas the overexpression of OPG in transgenic mouse models and OPG treatment of normal mice leads to osteopetrosis [66]. OPG can be measured in serum, plasma EDTA, citrate and heparin samples. There are commercially available sandwich ELISA assays for analyzing OPG by using a monoclonal capture and polyclonal detection antibodies [64]. However, the clinical use of serum OPG as a biomarker for evaluation of bone disease activity still needs additional demonstration. 


\section{Dickkopf-1 (DDK-1)}

DKK-1 and sclerostin are the inhibitors of Wnt signaling and are applied as bone remodeling biomarkers. DKK-1 is produced by osteoblasts and is secreted into circulation. The serum levels of DDK-1 reflect the inhibition of bone formation [67]. DKK-1 levels have decreased from $34.3 \mathrm{pmol} / \mathrm{L}$ at baseline to $29.7 \mathrm{pmol} / \mathrm{L}$ at the 24 -month of the breast cancer patients with anastrozole treatment [68]. DKK-1 has shown the correlation with the BMD of the femoral neck and of the total hip. Further long-term studies are necessary to identify the clinical application of the regulator DKK-1 as a biomarker for assessment of osteoporosis.

\section{Sclerostin}

In the presence of sclerostin, the Wnt pathway is downregulated and consequently osteoblastic differentiation is inhibited. Sclerostin is produced by osteocytes. Sclerostin is secreted into circulation, and serum levels reflect inhibition of bone formation [67]. In previous work, the concentrations of serum sclerostin have significantly increased from $29.5 \mathrm{pmol} / \mathrm{L}$ at baseline to $43.2 \mathrm{pmol} / \mathrm{L}$ after 24 months of treatment with anastrozole in breast cancer patients [68]. However, the clinical trial is further needed for the use of sclerostin as a biomarker of bone turnover.

\section{Conclusions}

In this mini-review, we reviewed several investigations and developments for the applications of bone biomarkers in the assessments of bone related diseases. From laboratory tests to clinical trials, the possibility of bone biomarkers to evaluate bone remodeling processes has been extensively demonstrated in physiological and pathological states. Bone biomarkers have shown great potential to serve as powerful indicators to evaluate the osteoporosis therapy and even to assist the clinical diagnosis of osteoporosis in the early stage. Among these bone biomarkers, P1NP has shown the great potential as a sensitive and stable bone biomarker for the early detection of osteoporosis.

\footnotetext{
Abbreviations

ALP: Total alkaline phosphatase; BALP: Bone-specific alkaline phosphatase; BMD: Bone mineral density; BSP: Bone sialoprotein; CTSK: Cathepsin K; CTX-1: Carboxy-terminal crosslinked telopeptide of type 1 collagen; DDK-1: dickkopf-1; DPD: Deoxypyridinoline; DXA: Dual-energy X-ray absorptiometry; HYL: Hydroxylysine; HYP: Hydroxyproline; NTX-1: Amino-terminal crosslinked telopeptide of type 1 collagen; OC: Osteocalcin; OP: Osteopontin; OPG: Osteoprotegerin; P1CP: Procollagen type 1 C-terminal propeptide; P1NP: Procollagen type $1 \mathrm{~N}$-terminal propeptide; PYD: Pyridinoline;

QCT: Quantitative computed tomography; RANKL: Receptor activator of NF-kB ligand; TRAP 5b: Tartrate-resistant acid phosphatase 5b (TRAP 5b); WHO: World Health Organization
}

Acknowledgements

We would like to thank the support from Taipei Medical University.
Funding

This work was supported by 105TMU-TMUH-09, TMU104-AE1-B28, MOST 105-2119-M-038-002 -MY2, MOST 103-2113-M-003-003-MY3, Taipei Medical University and Taipei Medical University Hospital.

Availability of data and materials

Not applicable.

Author's contributions

The present manuscript was drafted by TRK and revised by TRK and CHC. Both authors read and approved the final manuscript.

\section{Competing interest}

The authors declare that they have no competing interests.

Consent for publication

Not applicable.

Ethics approval and consent to participate

Not applicable.

\section{Author details}

${ }^{1}$ Graduate Institute of Nanomedicine and Medical Engineering, College of Biomedical Engineering, Taipei Medical University, Taipei 11031, Taiwan. ${ }^{2}$ International Ph.D. Program in Biomedical Engineering, College of Biomedical Engineering, Taipei Medical University, Taipei 11031, Taiwan. ${ }^{3}$ Bone and Joint Research Center, Department of Orthopedics and Traumatology, Taipei Medical University Hospital, Taipei 11031, Taiwan. ${ }^{4}$ School of Medicine, College of Medicine, Taipei Medical University, Taipei 11031, Taiwan.

Received: 15 March 2017 Accepted: 2 May 2017

Published online: 18 May 2017

\section{References}

1. Genant HK, Cooper C, Poor G, Reid I, Ehrlich G, Kanis J, et al. Interim report and recommendations of the World Health Organization task-force for osteoporosis. Osteoporos Int. 1999;10:259-64.

2. Pisani P, Renna MD, Conversano F, Casciaro E, Di Paola M, Quarta E, et al. Major osteoporotic fragility fractures: risk factor updates and societal impact. World J Orthop. 2016;7:171.

3. Leibson CL, Tosteson ANA, Gabriel SE, Ransom JE, Melton LJ. Mortality, disability, and nursing home use for persons with and without hip fracture: a population-based study. J Am Geriatr Soc. 2002;50:1644-50.

4. Lang TF, Guglielmi G, Van Kuijk C, De Serio A, Cammisa M, Genant HK. Measurement of bone mineral density at the spine and proximal femur by volumetric quantitative computed tomography and dual-energy X-ray Absorptiometry in elderly women with and without vertebral fractures. Bone. 2002:30:247-50.

5. Adams JE. Radiogrammetry and radiographic Absorptiometry. Radiol Clin N Am. 2010;48:531-40

6. Alexeeva L, Burkhardt P, Christiansen C, Cooper C, Delmas P, Johnell O, et al. Assessment of fracture risk and its application to screening for postmenopausal osteoporosis; 1994. p. 1-129.

7. Pisani P, Greco A, Renna M, Conversano F, Casciaro E, Quarta L, et al. An innovative ultrasound-based method for the identification of patients at high fracture risk; 2014. p. e50-e3.

8. Conversano F, Franchini R, Greco A, Soloperto G, Chiriaco F, Casciaro E, et al. A novel untrasound methodology for estimating spine mineral density. Ultrasound Med Biol. 2015;41:281-300.

9. Ferreira A, Alho I, Casimiro S, Costa L. Bone remodeling markers and bone metastases: from cancer research to clinical implications. BoneKEy reports. 2015;4

10. Eastell R, Hannon RA. Biomarkers of bone health and osteoporosis risk. Proc Nutr Soc. 2008:67:157-62.

11. Shi X, Li C, Liang B, He K, Li X. Weak cation magnetic separation technology and MALDI-TOF-MS in screening serum protein markers in primary type I osteoporosis. Genet Mol Res. 2014;14:15285-94.

12. He W-T, Wang B, Li M, Liang B-C, Shi Y-Z, Li X-Y, et al. Weak cation exchange magnetic beads coupled with MALDI-TOF-MS in screening serum 
markers in perimenopausal women with osteopenia. Int J Clin Exp Med. 2016;9:8136-44.

13. Liu L, Webster TJ. In situ sensor advancements for osteoporosis prevention, diagnosis, and treatment. Curr Osteoporos Rep. 2016;14:386-95.

14. Delmas PD, Eastell R, Garnero P, Seibel MJ, Stepan J, Comm Sci Advisors Int $\mathrm{O}$. The use of biochemical markers of bone turnover in osteoporosis. Osteoporos Int. 2000;11:2-17.

15. Compston J, Judd D, Crawley E, Evans W, Evans C, Church H, et al. Osteoporosis in patients with inflammatory bowel disease. Gut. 1987;28:410-5.

16. Fink HA, Litwack-Harrison S, Taylor BC, Bauer DC, Orwoll ES, Lee CG, et al. Clinical utility of routine laboratory testing to identify possible secondary causes in older men with osteoporosis: the osteoporotic fractures in men (MrOS) study. Osteoporos Int. 2016;27:331-8.

17. Kyd P, De Vooght K, Kerkhoff F, Thomas E, Fairney A. Clinical usefulness of bone alkaline phosphatase in osteoporosis. Ann Clin Biochem. 1998;35:717-25.

18. PetitClerc C. Quantitative fractionation of alkaline phosphatase isoenzymes according to their thermostability. Clin Chem. 1976;22:42-8.

19. Štěpán J, Volek $V$, Kolár J. A modified inactivation-inhibition method for determining the serum activity of alkaline phosphatase isoenzymes. Clin Chim Acta. 1976;69:1-9.

20. Whitaker KB, Whitby L, Moss D. Activities of bone and liver alkaline phosphatases in serum in health and disease. Clin Chim Acta. 1977; 80:209-19.

21. Behr W, Barnert J. Quantification of bone alkaline phosphatase in serum by precipitation with wheat-germ lectin: a simplified method and its clinical plausibility. Clin Chem. 1986;32:1960-6.

22. Schreiber WE, Whitta L. Alkaline phosphatase isoenzymes resolved by electrophoresis on lectin-containing agarose gel. Clin Chem. 1986;32:1570-3.

23. Van Hoof V, Lepoutre L, Hoylaerts M, Chevigne R, De Broe M. Improved agarose electrophoretic method for separating alkaline phosphatase isoenzymes in serum. Clin Chem. 1988;34:1857-62.

24. Gonchoroff DG, Branum EL, Cedel SL, Riggs BL, O'Brien JF. Clinical evaluation of high-performance affinity chromatography for the separation of bone and liver alkaline phosphatase isoenzymes. Clin Chim Acta. 1991; 199:43-50.

25. Crofton P. Wheat-germ lectin affinity electrophoresis for alkaline phosphatase isoforms in children: age-dependent reference ranges and changes in liver and bone disease. Clin Chem. 1992;38:663-70.

26. Day A, Saward S, Royle C, Mayne P. Evaluation of two new methods for routine measurement of alkaline phosphatase isoenzymes. J Clin Pathol. 1992;45:68-71.

27. Gomez B, Ardakani S, Ju J, Jenkins D, Cerelli MJ, Daniloff GY, et al. Monoclonal antibody assay for measuring bone-specific alkaline phosphatase activity in serum. Clin Chem. 1995;41:1560-6.

28. Lumachi F, Ermani M, Camozzi V, Tombolan V, Luisetto G. Changes of bone formation markers osteocalcin and bone-specific alkaline phosphatase in postmenopausal women with osteoporosis. Ann N Y Acad Sci. 2009;1173:E60-E3.

29. Lee NK, Sowa H, Hinoi E, Ferron M, Ahn JD, Confavreux $C$, et al. Endocrine regulation of energy metabolism by the skeleton. Cell. 2007;130:456-69.

30. Bharadwaj S, Naidu A, Betageri G, Prasadarao N, Naidu A. Milk ribonucleaseenriched lactoferrin induces positive effects on bone turnover markers in postmenopausal women. Osteoporos Int. 2009;20:1603-11.

31. Singh S, Kumar D, Lal AK. Serum osteocalcin as a diagnostic biomarker for primary osteoporosis in women. J Clin Diagn Res. 2015;9:RC04-7.

32. Garnero P, Vergnaud P, Hoyle N. Evaluation of a fully automated serum assay for total N-terminal propeptide of type I collagen in postmenopausal osteoporosis. Clin Chem. 2008;54:188-96.

33. Olsen BR, Guzman NA, Engel J, Condit C, Aase S. Purification and characterization of a peptide from the carboxy-terminal region of chick tendon procollagen type I. Biochemistry (Mosc). 1977;16:3030-6.

34. Smedsrød B, Melkko J, Risteli L, Risteli J. Circulating C-terminal propeptide of type I procollagen is cleared mainly via the mannose receptor in liver endothelial cells. Biochem J. 1990:271:345-50.

35. Hassager C, Jensen L, Johansen J, Riis B, Melkko J, Pødenphant J, et al. The carboxy-terminal propeptide of type I procollagen in serum as a marker of bone formation: the effect of nandrolone decanoate and female sex hormones. Metabolism. 1991;40:205-8.

36. Eriksen EF, Charles P, Melsen F, Mosekilde L, Risteli L, Risteli J. Serum markers of type I collagen formation and degradation in metabolic bone disease: correlation with bone histomorphometry. J Bone Miner Res. 1993;8:127-32.
37. Lowry M, Hall DE, Brosnan JT. Hydroxyproline metabolism by the rat kidney: distribution of renal enzymes of hydroxyproline catabolism and renal conversion of hydroxyproline to glycine and serine. Metabolism. 1985;34:955-61.

38. Jagtap VR, Ganu JV. Effect of antiresorptive therapy on urinary hydroxyproline in postmenopausal osteoporosis. Indian J Clin Biochem. 2012:27:90-3.

39. Prockop DJ, Kivirikko Kl, Tuderman L, Guzman NA. The biosynthesis of collagen and its disorders. N Engl J Med. 1979;301:77-85.

40. Delmas P, Eastell R, Garnero P, Seibel M, Stepan J, Foundation CoSAotlO The use of biochemical markers of bone turnover in osteoporosis. Osteoporos Int. 2000;11:S2-S17.

41. Cunningham LW, Ford JD, Segrest JP. The isolation of identical hydroxylysyl glycosides from hydrolysates of soluble collagen and from human urine. J Biol Chem. 1967;242:2570-1.

42. Cascio VL, Bertoldo F, Gambaro G, Gasperi E, Furlan F, Colapietro F, et al. Urinary galactosyl-hydroxylysine in postmenopausal osteoporotic women: a potential marker of bone fragility. J Bone Miner Res. 1999;14:1420-4.

43. Bettica P, Baylink D, Moro L. Galactosyl hydroxylysine and deoxypyridinoline: a methodological comparison. Clin Chem Lab Med. 1993:31:459-66.

44. Seibel MJ. Biochemical markers of bone turnover part I: biochemistry and variability. Clin Biochem Rev/Australian Association of Clinical Biochemists. 2005;26:97.

45. Seyedin SM, Kung VT, Daniloff YN, Hesley RP, Gomez B, Nielsen LA, et al. Immunoassay for urinary pyridinoline: the new marker of bone resorption. J Bone Miner Res. 1993;8:635-41.

46. Robins SP, Woitge H, Hesley R, Ju J, Seyedin S, Seibel MJ. Direct, enzymelinked immunoassay for urinary deoxypyridinoline as a specific marker for measuring bone resorption. J Bone Miner Res. 1994;9:1643-9.

47. Rosano TG, Peaston RT, Bone HG, Woitge HW, Francis RM, Seibel MJ. Urinary free deoxypyridinoline by chemiluminescence immunoassay: analytical and clinical evaluation. Clin Chem. 1998;44:2126-32.

48. Gerrits Ml, Thijssen J, Van Rijn H. Determination of pyridinoline and deoxypyridinoline in urine, with special attention to retaining their stability. Clin Chem. 1995:41:571-4.

49. Fisher LW, Whitson SW, Avioli LV, Termine JD. Matrix sialoprotein of developing bone. J Biol Chem. 1983;258:12723-7.

50. Fisher L, McBride O, Termine J, Young M. Human bone sialoprotein. Deduced protein sequence and chromosomal localization. J Biol Chem. 1990;265:2347-51.

51. Karmatschek M, Maier I, Seibel MJ, Woitge HW, Ziegler R, Armbruster FP. Improved purification of human bone sialoprotein and development of a homologous radioimmunoassay. Clin Chem. 1997;43:2076-82.

52. Fassbender W, Ruf T, Kaiser $H$, Stracke $H$. Serum levels of immunoreactive bone sialoprotein in osteoporosis: positive relations to established biochemical parameters of bone turnover, vol. 14. Athens: In vivo; 1999. p. 619-24.

53. Zhang Q, Wana JL, Sodek J. Characterization of the promoter region of the porcine opn (osteopontin, secreted phosphoprotein 1) gene. Eur J Biochem. 1992;207:649-59.

54. Chiang T-I, Chang I-C, Lee H-S, Lee H, Huang C-H, Cheng Y-W. Osteopontin regulates anabolic effect in human menopausal osteoporosis with intermittent parathyroid hormone treatment. Osteoporos Int. 2011:22:577-85.

55. Halleen JM, Alatalo SL, Suominen H, Cheng S, Janckila AJ, Väänänen HK. Tartrate-resistant acid phosphatase $5 \mathrm{~b}$ : a novel serum marker of bone resorption. J Bone Miner Res. 2000;15:1337-45.

56. Väänänen HK, Zhao H, Mulari M, Halleen JM. The cell biology of osteoclast function. J Cell Sci. 2000;113:377-81.

57. Chao T-Y, Yu J-C, Ku C-H, Chen MM, Lee S-H, Janckila AJ, et al. Tartrateresistant acid phosphatase $5 \mathrm{~b}$ is a useful serum marker for extensive bone metastasis in breast cancer patients. Clin Cancer Res. 2005;11:544-50.

58. Nenonen A, Cheng S, Ivaska KK, Alatalo SL, Lehtimäki T, Schmidt-Gayk H, et al. Serum TRACP $5 b$ is a useful marker for monitoring alendronate treatment: comparison with other markers of bone turnover. J Bone Miner Res. 2005;20:1804-12.

59. Baim S, Miller PD. Perspective: assessing the clinical utility of serum CTX in postmenopausal osteoporosis and its use in predicting risk of osteonecrosis of the jaw. J Bone Miner Res. 2009;24:561-74.

60. Christgau S. Circadian variation in serum CrossLaps concentration is reduced in fasting individuals. Clin Chem. 2000:46:431.

61. Pérez-Castrillón JL, Pinacho F, De Luis D, Lopez-Menendez M, Dueñas LA. Odanacatib, a new drug for the treatment of osteoporosis: review of the results in postmenopausal women. J Osteoporos. 2010;2010:401581. 
62. Holzer G, Noske H, Lang T, Holzer L, Willinger U. Soluble cathepsin K: a novel marker for the prediction of nontraumatic fractures? J Lab Clin Med. 2005;146:13-7.

63. Wu K, Lin T-H, Liou H-C, Lu D-H, Chen Y-R, Fu W-M, et al.

Dextromethorphan inhibits osteoclast differentiation by suppressing RANKLinduced nuclear factor-KB activation. Osteoporos Int. 2013;24:2201-14.

64. Rogers A, Eastell R. Circulating osteoprotegerin and receptor activator for nuclear factor $\mathrm{kB}$ ligand: clinical utility in metabolic bone disease assessment. J Clin Endocrinol Metab. 2005;90:6323-31.

65. Yasuda H, Shima N, Nakagawa N, Yamaguchi K, Kinosaki M, S-i M, et al. Osteoclast differentiation factor is a ligand for osteoprotegerin/ osteoclastogenesis-inhibitory factor and is identical to TRANCE/RANKL. Proc Natl Acad Sci U S A. 1998:95:3597-602.

66. Yasuda H, Shima N, Nakagawa N, Mochizuki S-I, Yano K, Fujise N, et al. Identity of osteoclastogenesis inhibitory factor (OCIF) and osteoprotegerin (OPG): a mechanism by which OPG/OCIF inhibits osteoclastogenesis in vitro 1. Endocrinology. 1998;139:1329-37.

67. Anastasilakis AD, Polyzos SA, Gkiomisi A, Bisbinas I, Gerou S, Makras P. Comparative effect of zoledronic acid versus denosumab on serum sclerostin and dickkopf-1 levels of naive postmenopausal women with low bone mass: a randomized, head-to-head clinical trial. J Clin Endocrinol Metab. 2013:98:3206-12.

68. Kyvernitakis I, Rachner TD, Urbschat A, Hars O, Hofbauer LC, Hadji P. Effect of aromatase inhibition on serum levels of sclerostin and dickkopf-1, bone turnover markers and bone mineral density in women with breast cancer. J Cancer Res Clin Oncol. 2014;140:1671-80.

\section{Submit your next manuscript to BioMed Central} and we will help you at every step:

- We accept pre-submission inquiries

- Our selector tool helps you to find the most relevant journal

- We provide round the clock customer support

- Convenient online submission

- Thorough peer review

- Inclusion in PubMed and all major indexing services

- Maximum visibility for your research

Submit your manuscript at www.biomedcentral.com/submit 